\title{
SYSTEMATIC PARAMETER ESTIMATION OF WATERSHED ACIDIFICATION MODEL
}

\author{
FI-JOHN CHANG \\ Department of Agricultural Engineering, National Taiwan University, Taipei, Taiwan, ROC \\ AND \\ J. W. DELLEUR \\ School of Civil Engineering, Purdue University, West Lafayette, IN 47907, U.S.A.
}

\begin{abstract}
A joint strategy for parameter estimation which can systematically identify the important model parameters is presented. The strategy includes a regionalized sensitivity analysis (RSA) and an automatic parameter calibration technique (APCT). The RSA is based on a large number of Monte-Carlo simulations to identify the sensitive parameters and to establish a range of appropriate values for each sensitive parameter. The APCT adjusts the values of the sensitive parameters based on changes in the residual variances between the predicted and observed values. The strategy is applied to the watershed acidification model-ILWAS. The strategy succeeds in identifying the sensitive parameter and increases the likelihood of obtaining a global optimal parameter set. Improvements in the model prediction of the streamflow and chemistry are obtained.
\end{abstract}

KEY WORDS

\section{INTRODUCTION}

The increasingly widespread acid deposition which is associated with forest decline and fish degeneration has become one of the most important current environmental issues. Several regions of the United States, Canada, Sweden, and Norway have been reported to have precipitation that is very acidic ( $\mathrm{pH}$ less than $4 \cdot 2$ ). Because of the complexity of the interactions of deposited substances moving through ecosystems, the identification of the mechanisms of freshwater acidification has proven to be difficult. One method of improving our understanding of the acidification mechanisms is the development of physicochemically based mathematical models of the quantitative linkage between acid deposition and terrestrial and aquatic ecosystems. By using a process-oriented strategy, the ILWAS (Integrated Lake-Watershed Acidification Study) model was developed to make the quantitative linkage between atmospheric deposition and surface water chemistry in lakes of the Adirondack Mountains of New York State (Chen et al., 1982, $1983 \mathrm{a}, \mathrm{b}$; Goldstein et al., $1984 \mathrm{a}$ and b). The ILWAS model is the most complete simulator of the hydrologic and ecological effects of acid deposition on watersheds available today. However, due to the detailed processes involved it includes a large number of parameters. Because of the parameter uncertainty, the ILWAS model, like other sophisticated models, has not always given the anticipated improvement in predicting the state of the system, as compared to simpler models. Consequently, the problem of parameter estimation is of major importance for its overall performance and general application.

Two parameter estimation methods commonly used in hydrologic studies are manual and automatic techniques (Sorooshian, 1978). The manual estimation is a trial and error procedure by which the parameters of values of a model are adjusted subjectively, based on specific characteristics of the output of previous computer runs. This method requires a great amount of time and considerable skill and experience with the model and knowledge of the area to which it is being applied. The automatic estimation method, on the other hand, utilizes systematic optimization techniques to adjust the values of unknown parameters based on 
changes in the values of a mathematical error function. The automatic method does not require extensive familiarity with the model being used and reduces the need for personal judgment on parameter changes. Simplicity of application and execution speed have made this method a very popular tool in hydrologic modelling. In particular, it facilitates the use of complex watershed acidification models.

However, there are some long-standing inherent disadvantages to the automatic parameter estimation. The most familiar is the common result that many combinations of parameter values provide equally good fits of the model to the data. There is, therefore, ambiguity in the interpretation of past behaviour and this is likely to propagate forward into an ambiguous prediction of future behaviour. Secondly, there could be multiple local optima on the objective function surface. A conjunction of interdependent parameters and the local optimum clearly could create severe difficulties for the successful application of an automatic technique. In an attempt to overcome this difficulty, a regionalized sensitivity analysis is performed first. It indicates the relative significance of the parameters, identifies the important parameters defining the model response, and establishes a range of values appropriate for each sensitive parameter. This way the automatic parameter calibration can be efficiently performed and the global optimal solution is more likely to be reached.

The purpose of this paper is to develop a systematic parameter estimation strategy and to investigate the usefulness of its implementation on the ILWAS model.

\section{METHODS}

\section{Calibration strategy}

The systematic parameter estimation strategy consists of a regionalized sensitivity analysis followed by an automatic parameter estimation technique. The procedures are as follows:

Regionalized Sensitivity Analysis (RSA). The RSA attempts to identify the segments of the model that are most important to a successful simulation (Hornberger and Spear, 1981). The procedure of this method is given in the following:

1. Parameter selection. Select the parameters to be tested.

2. Parameter ranges. Define the design ranges of the selected parameters. The ranges of parameters may be obtained from the literature or from experience. A wide range is recommended on the first trial.

3. Random number generation. For each selected parameter, generate a series of, for example, 300 independent random numbers with a uniform distribution within the design range.

4. Monte-Carlo Simulation. Randomly select a sample from each series to form a parameter set and run the model using this particular set of parameter values. Whether a parameter set is acceptable or unacceptable is based on a criterion, $R$, which represents the model improvement over the mean observed values:

$$
R=\frac{\sum_{i=1}^{n}\left(\bar{x}-x_{i}\right)^{2}-\sum_{i=1}^{n}\left(\hat{x}_{i}-x_{i}\right)^{2}}{\sum_{i=1}^{n}\left(\bar{x}-x_{i}\right)^{2}}
$$

where $n$ is the number of observations; $x_{i}$ are observed values, $i=1$ to $n ; \bar{x}$ is their mean; and $\hat{x}_{i}$ are the predicted values. The criterion $R$ is similar to the coefficient of determination in correlation analysis which is the proportion of the total variation explained by the model. If the $R$ value obtained from the simulation is greater than a subjective $R$ value then the result is acceptable, otherwise the result is unacceptable.

5. Comparison of distributions. For each parameter, compare the distributions of the parameter values associated with the acceptable and unacceptable results. The Kolmogorov-Smirnov (K-S) test at a level of significance of, for example, 5 per cent is used to classify whether or not the two distributions are significantly different. If the two functions are not statistically different, then the parameter is insensitive for the simulation of that particular set of results; otherwise the parameter is sensitive. For the insensitive parameters, specific values within the previously designed ranges are assigned. For the sensitive 
parameters, the range of values is reduced to the favourable range which is taken as the range of values occurring most often and corresponds to the range of values for which the plot of the cumulative distribution of the acceptable results is steepest. The method makes it possible to focus on a small number of important parameters in the model.

Automatic Parameter Calibration Technique (APCT) The APCT was developed so that the parameters can be automatically estimated without manual adjustment. The procedure is summarized as follows:

1. Select the parameters to be optimized. In an elaborate model like ILWAS it is not possible to optimize all the parameters. Only the sensitive parameters identified by the RSA method or a subset thereof can be included. The parsimony of parameters is advisable because an increase in the number of parameters to be optimized leads to more iterative executions. Moreover, a large number of parameters does not necessarily imply better results due to the inherent nonlinearities in the model structure and the increased likelihood of finding multiple local optima of the objective function surface.

2. Define a reasonable range of values for each parameter considered. Because wide parameter ranges are more likely to cause local optima, it is recommended to use the favourable parameter ranges identified in the RSA method.

3. Give several initial sets of the parameter values. Several initial sets of the parameter values are used in the simulations in order to avoid getting a locally optimal solution.

4. Define the objective function. The $R$ value given in Equation 1 is used as the objective function. The objective is then to maximize the $R$ value. The $R$ value is calculated immediately after each simulation.

5. Optimize each parameter in sequence. In this study, the Golden Section method (Luenberger, 1984) is used to find the parameter value giving the maximum $R$ value. After all parameters are optimized, an optimization cycle is complete. The value of the objective function $(R)$ is stored at the end of each cycle.

6. Return to step 5 and repeat the optimization cycle until the $R$ value does not increase by more than a small amount, for example, 0.001 .

A flow chart of the APCT procedure is shown in Figure 1.

\section{Model used}

The joint strategy was implemented for the ILWAS model to simplify its use and to improve its performance.

The ILWAS model was developed by Chen et al. (1983b) for the Electric Power Research Institute (EPRI) to establish a quantitative link between acid deposition and lake acidification and to assess various mitigation strategies for acid rain (Goldstein et al., 1984; Gherini et al., 1985). To simulate the spatial heterogeneity in a watershed system, the ILWAS model conceptualizes the system in drainage subcatchments, stream segments (if any), and lake(s). Each subcatchment contains compartments representing canopy, snowpack, and soil layers. The lake is divided into horizontally mixed layers to allow for calculation of temperature and water quality profiles.

Basically, the model is composed of hydrologic and chemical modules, both split into a number of submodels. The hydrologic module routes precipitation from the vegetative canopy to lake outlet. The chemical module calculates the $\mathrm{pH}$, the concentrations of alkalinity, the major cations $\left(\mathrm{Ca}^{2+}, \mathrm{Mg}^{2+}, \mathrm{K}^{+}, \mathrm{Na}^{+}\right.$, and $\left.\mathrm{NH}_{4}^{+}\right)$and anions $\left(\mathrm{SO}_{4}^{2-}, \mathrm{NO}_{3}^{-}, \mathrm{Cl}^{-}\right.$, and $\left.\mathrm{F}^{-}\right)$, monomeric aluminum and its organic and inorganic complexes, organic acid analogues, and dissolved inorganic carbon. Schematic and processes summaries of the ILWAS model are shown in Figure 2.

\section{Data}

Two test watersheds were used, the Panther watershed and the Walker Branch watershed. The Panther watershed is one of three watersheds located in the Adirondack Mountains, New York, which were studied as part of the ILWAS project. Panther watershed hydrological basin has an area of $1.24 \mathrm{~km}^{2}$. The basin is covered predominately by thick glacial till, averaging $24.5 \mathrm{~m}$ in depth. The detail description of vegetation and soil geochemistry of the Panther watershed can be found from Cronan (1985) and April and Newton 


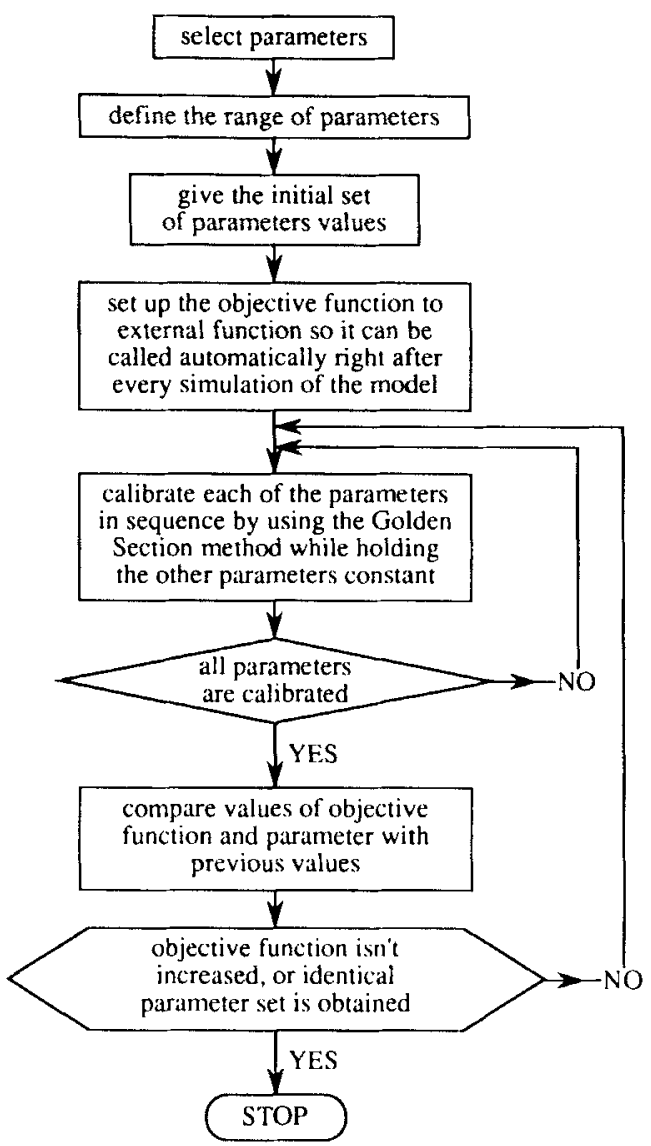

Figure 1. Flow chart of the APCT method

(1985). The input data files of Panther watershed, which were supplied by EPRI, are used in the simulation. The data files include model coefficients, observed meteorologic data, and wet and dry deposition chemistry for three years (1978-1981). The observed outflow, its $\mathrm{pH}$ and sulphate concentration in the outflow are compared to the model prediction, so that the accuracy of the model performance can be obtained and the parameters can be automatically adjusted. The first year data were used for RSA and APCT calibration. The last two years data were used for model verification performance evaluation of the RSA/APCT procedure by comparison of the predictions and the observations.

The Walker Branch watershed is a 97 hectare $\left(0.97 \mathrm{~km}^{2}\right)$ forested catchment located in the Oak Ridge Reservation about $3 \mathrm{~km}$ east of the Oak Ridge National Laboratory (ORNL) at Oak Ridge, Tennessee. The site has been described by Harris (1977), and the hydrologic characteristics have been described by Henderson et al. (1977). The watershed has a predominantly mixed oak-hickory forest cover over soil that varies in thickness from more than $30 \mathrm{~m}$ at ridgetops to about $2 \mathrm{~m}$ or less along the main channels. More than 90 per cent of the catchment area is covered by either Fullerton cherty silt loam or Bodine cherty silt loam soils, which are welldrained (Harris, 1977). The three years, 1969-1972, hydrologic data sets (included daily rainfall, temperature, and runoff) and water chemistry data (included the weekly concentration of $\mathrm{Ca}, \mathrm{Mg}, \mathrm{K}$, and $\mathrm{Na}$ in the wet and dry deposition and stream flow) were obtained from ORNL, Tennessee. The first year data were used for calibration, and the last two years data were used for verification in this study. It is to be noted that the data for the Walker Branch watershed were not collected specifically for the purpose of running the ILWAS model, so that some of the data that were available for the Panther watershed were not available for the Walker Branch. 


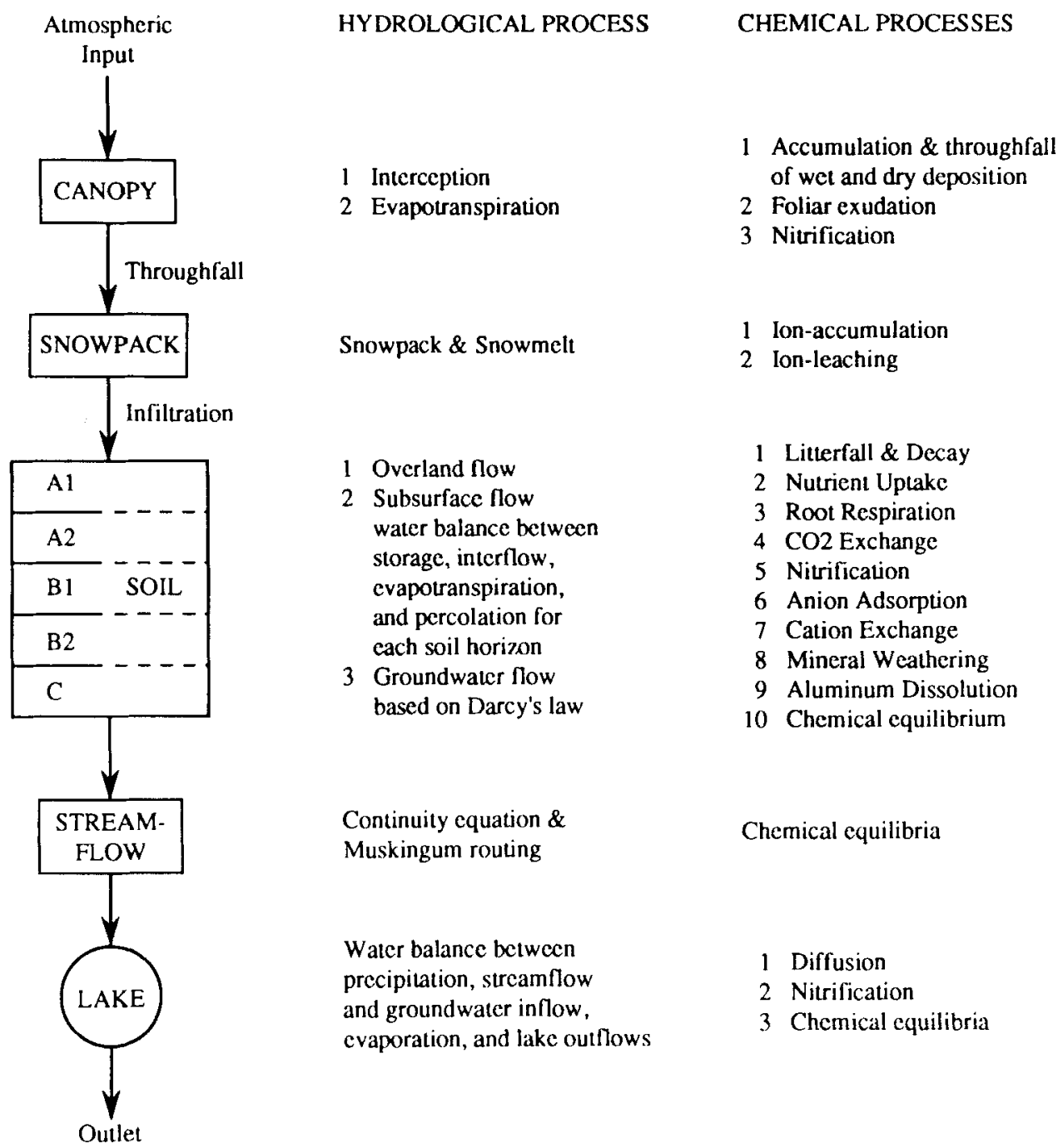

Figure 2. Schematic and major processes of the ILWAS model

\section{RESULTS}

The results of the RSA/APCT techniques are discussed first for the application of the hydrologic portion, then for the chemical portion of ILWAS for the simulation of Panther Creek. This section concludes with the presentation of the results obtained by the systematic parameter estimation strategy applied to the Walker Branch watershed.

\section{Application of the RSA to hydrologic portion of ILWAS Model, Panther watershed}

Because the hydrologic flow paths are critical to the understanding of the chemical reactions of the surface and subsurface water (Chen et al., 1982), the hydrologic portion of the ILWAS model was fitted first. In particular, the soil compartment of the ILWAS model has a significant influence on the outflow $\mathrm{pH}$ (Chen et al., 1982; Chang, 1988). The soil compartment was thus investigated first in detail. For the simulation, the Panther watershed was divided into five draining subcatchments and each subcatchment included five soil layers. If all soil parameters in each subcatchment and in each layer were to be considered independently, the 
number of parameters would be too large. Besides, some parameters would only have a very small effect. Instead, the RSA was performed. The RSA was based on the type of parameter (i.e. the soil layer thickness, the soil moisture, etc.) so that the same percentage of increase or decrease for each type of parameter was executed for each subcatchment and soil layer.

Six soil parameters which show a high degree of correlation with streamflow were chosen for this study. One of these parameters is SOIL MOISTURE which includes the initial soil moisture (THETA), the field capacity (THEFC), and the saturation moisture (THETS). These three parameters were changed similarly because of the several constraints in the model which do not allow these parameters to be generated independently. For example, the saturation moisture must be greater than the field capacity. The remaining parameters correlated with streamflow are the horizontal and vertical permeabilities (PERM and SMI), the soil layer thickness (THICK), the fraction of root distribution for the layer (ETWGHT), and the initial soil temperature (SOLTMP). The ranges of all the parameters were set between 0.5 to 1.5 times their values used by Goldstein et al. (1984b).

All the 300 Monte-Carlo simulation results were very good as the $R$ values were within the range 0.61 to 0.79 . The classification criterion of the results as acceptable or unacceptable is, thus, very sensitive and must be carefully defined. Five different subjective $R$ values were used and they are shown in Table I along with the Kolmogorov-Smirnov $(\mathrm{K}-\mathrm{S})$ test results. The $p$ values of parameter THICK are much smaller than 5 per cent in all cases, so THICK is classified as sensitive. The SOIL MOISTURE and SOLTMP are classified as insensitive because their $p$ values are much larger than 5 per cent in all cases. The parameters PERM, SMI, and ETWGHT are classified as moderately sensitive because their $p$ values are around 5 per cent. In general, the five different $R$ values produce similar classifications of the parameters as sensitive or insensitive. This indicates that the selection of a cutoff value of the criterion $R$ for classifying simulations as acceptable or unacceptable is robust.

The cumulative distributions of the acceptable and unacceptable responses of the parameters of case 3 are shown in Figure 3. The cumulative distributions of parameter THICK are seen to be significantly different and the favourable simulation range is approximately from 0.65 to 1.15 , while the distributions of the other parameters are not significantly different.

Application of the APCT to hydrologic portion of ILWAS model, Panther watershed

Three cases are investigated. Case 1 includes one sensitive parameter (THICK) and case 2 includes one sensitive and the three moderately sensitive parameters (PERM $<$ SMI and ETWGHT) which were identified in the previous section. Case 3 includes all six parameters. A range is defined for each coefficient (Table II). The coefficient boundaries of case 1 and case 2 were limited to the favourable ranges obtained

Table I. Result of $\mathbf{K}-\mathrm{S}$ test ( $p$ values*) for the ILWAS model (hydrology portion) applied to the Panther watershed

\begin{tabular}{lccccc}
\hline Variables & CASE 1 & CASE 2 & CASE 3 & CASE 4 & CASE 5 \\
& $R=0.722$ & $R=0.73$ & $R=0.735$ & $R=0.74$ & $R=0.745$ \\
\hline SOIL MOISTURE & 0.2082 & 0.5045 & 0.6862 & 0.7935 & 0.4473 \\
PERM & 0.0185 & 0.2204 & 0.1375 & 0.1155 & 0.1742 \\
THICK & 0.0004 & 0.0018 & 0.0002 & 0.0002 & 0.0000 \\
SMI & 0.0019 & 0.0424 & 0.1066 & 0.0660 & 0.1670 \\
ETWGHT & 0.0719 & 0.1294 & 0.0336 & 0.0273 & 0.0859 \\
SOLTMP & 0.8625 & 0.8632 & 0.7170 & 0.4758 & 0.5713 \\
Accepted responses & 182 & 171 & 152 & 139 & 114 \\
Rejected responses & 108 & 129 & 148 & 161 & 186 \\
\hline
\end{tabular}

* The $p$ value is defined as the smallest level of significance that would lead to the rejection of the null hypothesis. (Hines and Montgomery, 1990). The null hypothesis is that the distribution of the parameter values corresponding to the satisfactory and unsatisfactory cases are not significantly different, i.e. the parameter is insensitive 

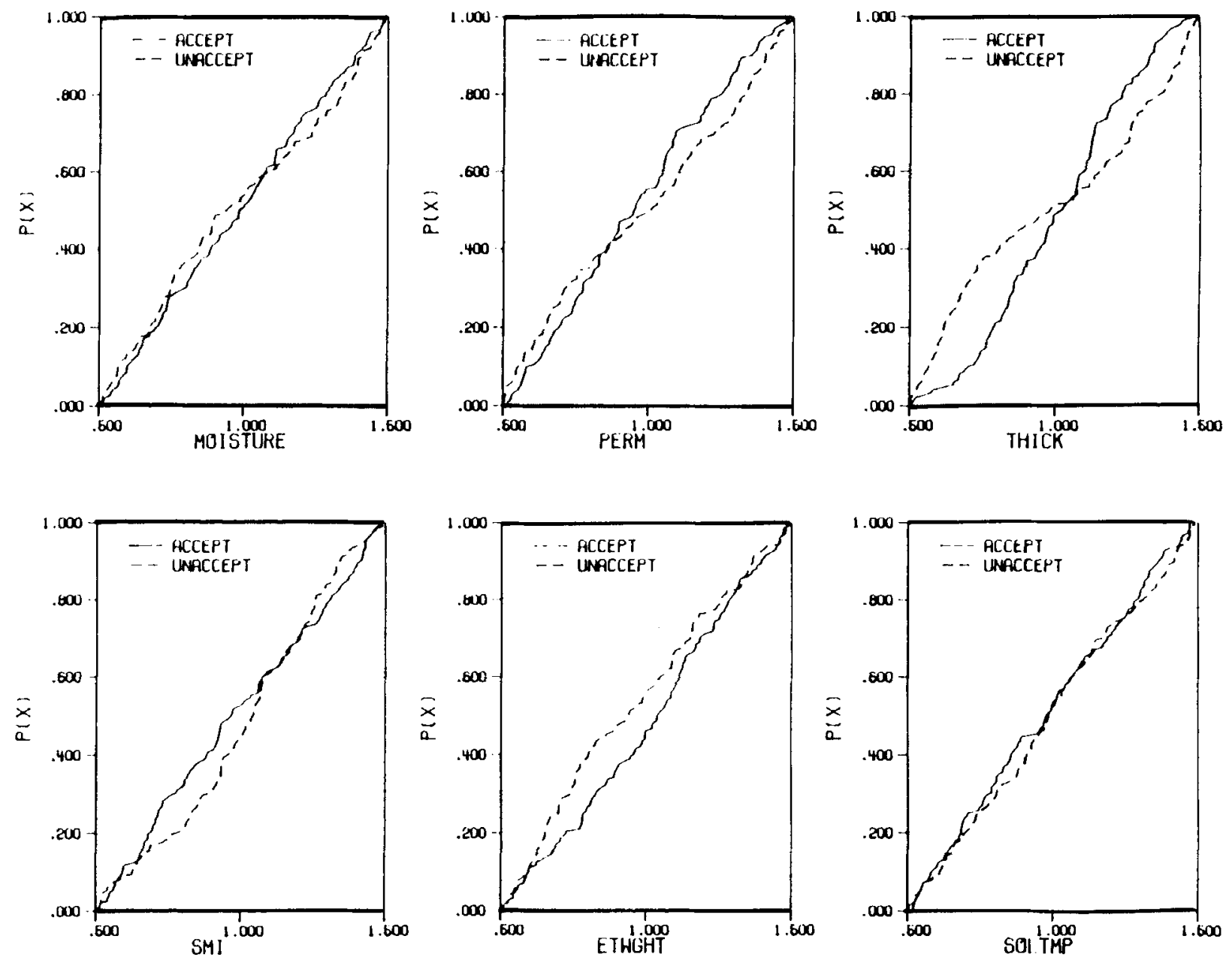

Figure 3. The two cumulative distribution for six soil hydrologic parameters. Abscissa represents the ratio of the parameter value to its original value

Table II. The APCT results of the ILWAS model (hydrologic portion) applied to the Panther watershed

\begin{tabular}{llcccccccc}
\hline Case & Sources & MOISTURE & PERM & THICK & SMI & ETWGHT & SOLTMP & $N$ & $R$ \\
\hline 1 & initial & $1.0^{*}$ & 1.0 & 1.0 & 1.0 & 1.0 & 1.0 & & \\
& range & - & - & $0.65-1.15$ & - & - & - & & \\
& optimal value & 1.0 & 1.0 & 1.075 & 1.0 & 1.0 & 1.0 & 13 & 0.773 \\
2 & initial & 1.0 & 1.0 & 1.0 & 1.0 & 1.0 & 1.0 & & \\
& range &.- & $0.7-1.35$ & $0.65-1.15$ & $0.55-1.15$ & $0.7-1.35$ & - & & \\
& optimal value & 1.0 & 1.060 & 1.008 & 0.55 & 1.205 & 1.0 & 142 & 0.780 \\
3 & initial & 1.0 & 1.0 & 1.0 & 1.0 & 1.0 & 1.0 & & \\
& range & $0.5-1.5$ & $0.5-1.5$ & $0.5-1.5$ & $0.5-1.5$ & $0.5-1.5$ & $0.5-1.5$ & & \\
& optimal value & 1.1950 & 0.998 & 1.002 & 0.50 & 1.054 & 1.375 & 217 & 0.786
\end{tabular}

* Values shown in the table are ratios of the specified parameter values to their original values. The original values of the parameters were supplied by EPRI as part of the ILWAS tape (Goldstein et al., 1984b). The last column shows the number of iterations $N$, and the acceptability criterion $R$. 
from the Monte-Carlo simulation in the previous section. The coefficient boundaries of case 3 were set as 0.5 and 1.5 .

A comparison of the $R$ value of the original case, without using the APCT procedure $(0.767)$, with the $R$ values obtained from APCT procedure shown in Table II ( 0.773 to 0.786$)$ shows a small improvement. The optimal solution of the sensitive parameter, THICK, is very close to 1.0 , i.e. the optimal value is essentially the original value. This indicates that the original values (Goldstein et al., 1984b) of parameter set THICK were well estimated and the systematic parameter estimation strategy was successful in finding the optimal solution for the sensitive parameters.

\section{Application of the joint strategy to chemical portion of ILWAS model}

In general, the soil buffering capacity is provided by ion-exchange and chemical weathering. Ion-exchange is believed to be rapid and is an important soil process. The dissolution of mineral through the consumption of $\mathrm{H}^{+}$-ion and the liberation of basic cations provides the long-term neutralizing capacity of a catchment. The ILWAS model uses the Gapon expressions for ion-exchange and specifies individual mineral dissolution according to a given stoichiometry. Both processes include several parameters which need to be specified. Unfortunately, these parameters are not well known. Several parameters which relate to these two processes were chosen for testing their sensitivity. Again, only the types of the parameters were tested because it is impractical to test all the parameters in each subcatchment and each soil layer individually. The ILWAS model simulates the concentrations of all major cations and anions. In this study, however, only hydrogen and sulphate concentrations were used as index of the model overall performance.

Seven soil parameters which correlate with streamflow hydrogen and sulphate concentrations were chosen. These are: CKMELT, CKEH, CKSO, CKMNRL, CEC, SOLION(3), and SOLION(4). CKMELT is the snowmelt leaching coefficient. CKEH is the cation exchange coefficient for $\mathrm{H}^{+}$. CKSO is the anion adsorption coefficient for sulphate. CKMNRL is the weathering rate. CEC is the cation exchange capacity. SOLION(3) and SOLION(4) are the dissolved hydrogen and sulphate ions in soil solution, respectively.

The acceptability criterion, $R$, was set equal to the average of the criteria $R I$ and $R 2$ calculated by equation 1 with $\bar{x}, \hat{x}$ and $x_{i}$ representing the mean, the estimate, and the observed values of the $\mathrm{pH}$ or of the sulphate concentration, respectively. The RSA procedure was performed first. Several different sets of $R$ values were used as classification criteria. The $K-S$ test results show that the parameters CKSO and CKEH are sensitive, while the other parameters are insensitive (Table III). The cumulative distributions of the acceptable and unacceptable responses of the seven parameters are shown in Figure 4. The cumulative distributions of the parameter CKSO appear to be very different while the distributions of CKEM are somewhat different, confirming the results of the $\mathrm{K}-\mathrm{S}$ test.

Two cases were investigated for the APCT procedure: one includes the two sensitive parameters (CKEH and CKSO), identified in the RSA method, the other includes the seven parameters shown in Table IV. The objective function was the overall model performance, the index $R$.

Table III. Results of K-S test ( $p$ values) for the ILWAS model (chemical portion) applied to the Panther watershed

\begin{tabular}{lcccc}
\hline Variables & & $R$ & & Sensitive \\
& -0.2 & -0.1 & 0.0 & \\
\hline CKMELT & 0.84 & 0.59 & 0.18 & NO \\
CKEH & 0.23 & 0.44 & 0.14 & YES \\
CKSO & 0.00 & 0.00 & 0.00 & YES \\
CKMNRL & 0.77 & 0.25 & 0.64 & NO \\
CEC & 0.93 & 0.97 & 0.99 & NO \\
SOLION(3) & 0.35 & 0.29 & 0.28 & NO \\
SOLION(4) & 0.41 & 0.18 & 0.80 & NO \\
Accepted number & 156 & 127 & 89 & \\
Rejected number & 124 & 173 & 211 & \\
\hline
\end{tabular}



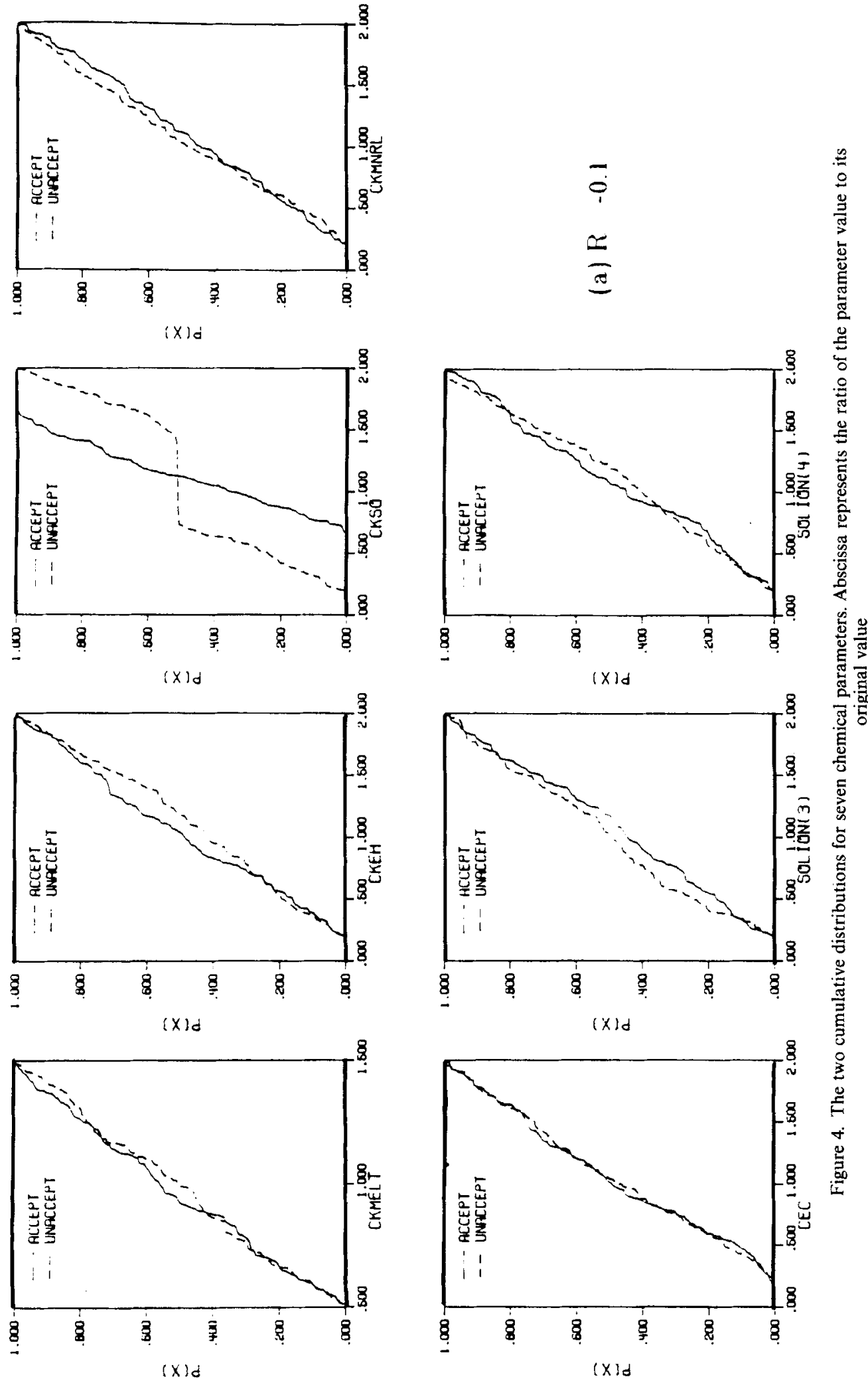
Table IV. The APCT results of the ILWAS model (chemical portion) applied to the Panther watershed

\begin{tabular}{|c|c|c|c|c|c|c|c|c|c|c|}
\hline Case & Sources & CKMELT & CKEH & CKSO & CKMNRL & CEC & $\begin{array}{l}\text { SOLION } \\
\text { (3) }\end{array}$ & $\begin{array}{c}\text { SOLION } \\
(4)\end{array}$ & $N$ & $R$ \\
\hline \multirow[t]{3}{*}{1} & initial & $1.0^{*}$ & 1.0 & 1.0 & 1.0 & 1.0 & $1 \cdot 0$ & 1.0 & & \\
\hline & range & - & $0.45-1.32$ & $0.8-1.4$ & $\ldots-$ & - & -- & $\ldots$ & & \\
\hline & optimal value & 1.0 & 0.75 & 0.998 & 1.0 & 1.0 & 1.0 & 1.0 & 27 & 0.204 \\
\hline \multirow[t]{3}{*}{2} & initial & $1 \cdot 0$ & 1.0 & 1.0 & 1.0 & 1.0 & $1 \cdot 0$ & 1.0 & & \\
\hline & range & $0.2-1.5$ & $0.45-1.32$ & $0.8-1.4$ & $0.2-2.0$ & $0 \cdot 2-2 \cdot 0$ & $0 \cdot 2-2 \cdot 0$ & & & \\
\hline & optimal value & 0.2 & 0.695 & 1.045 & $2 \cdot 0$ & 0.888 & 0.463 & 1.900 & 189 & 0.233 \\
\hline
\end{tabular}

* Values shown in the table are ratios of the specified parameter values to their original values (Goldstein et al., 1984b). The last column shows the number of iterations, $N$ and the acceptability criterion $R$.

The parameter boundaries of case 1 were limited to the favourable ranges of the Monte-Carlo simulation. The results show that the optimal value of the most sensitive parameter, CKSO, is very close to its original value; however, the optimal value of the other sensitive parameter, $\mathrm{CKEH}$, is equal to 0.75 times of its original value. The optimal $R$ value is equal to 0.204 and the number of iteration was 27 . Case 2 includes seven parameters. The sensitive parameter boundaries were the same as case 1 ; the insensitive parameter boundaries were the same as those of the Monte-Carlo simulation. The optimal $R$ value is equal to 0.223. Although the optimal $R$ value is slightly better than in case 1 , the number of iterations to reach the optimal solution (189) is much greater than that of case 1 . The results demonstrate that the joint RSA-APCT strategy is of great worth, because the computation time is greatly reduced. This is a critical consideration as each simulation is very long for the integrated acidification model.

Following the calibration of the model for the period of 1 September, 1978 to 31 August, 1979, a continuous simulation for the period of 1 September, 1977 to 31 August, 1981 was performed without further adjustment of the parameters.

These verification results are shown in Table $\mathrm{V}$ and Figure 5. The model fits the streamflow chemistry reasonably well. The correlation between the observed outflow $\mathrm{pH}$ and the model predicted value is around 0.65 and the correlation between the observed outflow sulphate concentration and model predicted value is about 0.4 . The low $R$ values (around 0.1 ) are due to the very wide fluctuations of observed $\mathrm{pH}$ and sulphate concentration. In summary, the systematic parameter estimation strategy was implemented for the ILWAS model and it was demonstrated that this strategy can systematically identify the sensitive parameters and improve the model performance.

Table V. Chemical verification results using the optimal values from APCT method applied to the Panther watershed

\begin{tabular}{lcccccccccc}
\hline Case & CKMELT & CKEH & CKSO & CKMNRL & CEC & $\begin{array}{c}\text { SOLION } \\
(3)\end{array}$ & $\begin{array}{c}\text { SOLION } \\
(4)\end{array}$ & $R^{\ddagger}$ & $R I^{\ddagger}$ & $R 2^{\ddagger}$ \\
\hline $0^{*}$ & $1.0 \dagger$ & 1.0 & 1.0 & 1.0 & 1.0 & 1.0 & 1.0 & 0.82 & 0.646 & 0.398 \\
1 & 1.0 & 0.75 & 0.998 & 1.0 & 1.0 & 1.0 & 1.0 & 0.140 & 0.659 & 0.398 \\
2 & 0.121 & 0.695 & 1.045 & 0.783 & 0.888 & 0.463 & 1.9 & 0.94 & 0.649 & 0.398 \\
\hline
\end{tabular}

* Case 0 corresponds to the original parameter values (hand calibration, EPSC 1988). Cases 1 and 2 correspond to the optimal values of cases 1 and 2, respectively of Table IV.

${ }^{\dagger}$ Values shown in the table are ratios of the specified parameter values to their original values (Goldstein et al., 1984b), except for the last column where $R$ is the acceptability criterion, $R 1$ and $R 2$ are the correlation coefficients between observed and simulated outflow $\mathrm{Ph}$ and $\mathrm{SO}_{4}$ concentration, respectively.

* After removing outliers. 

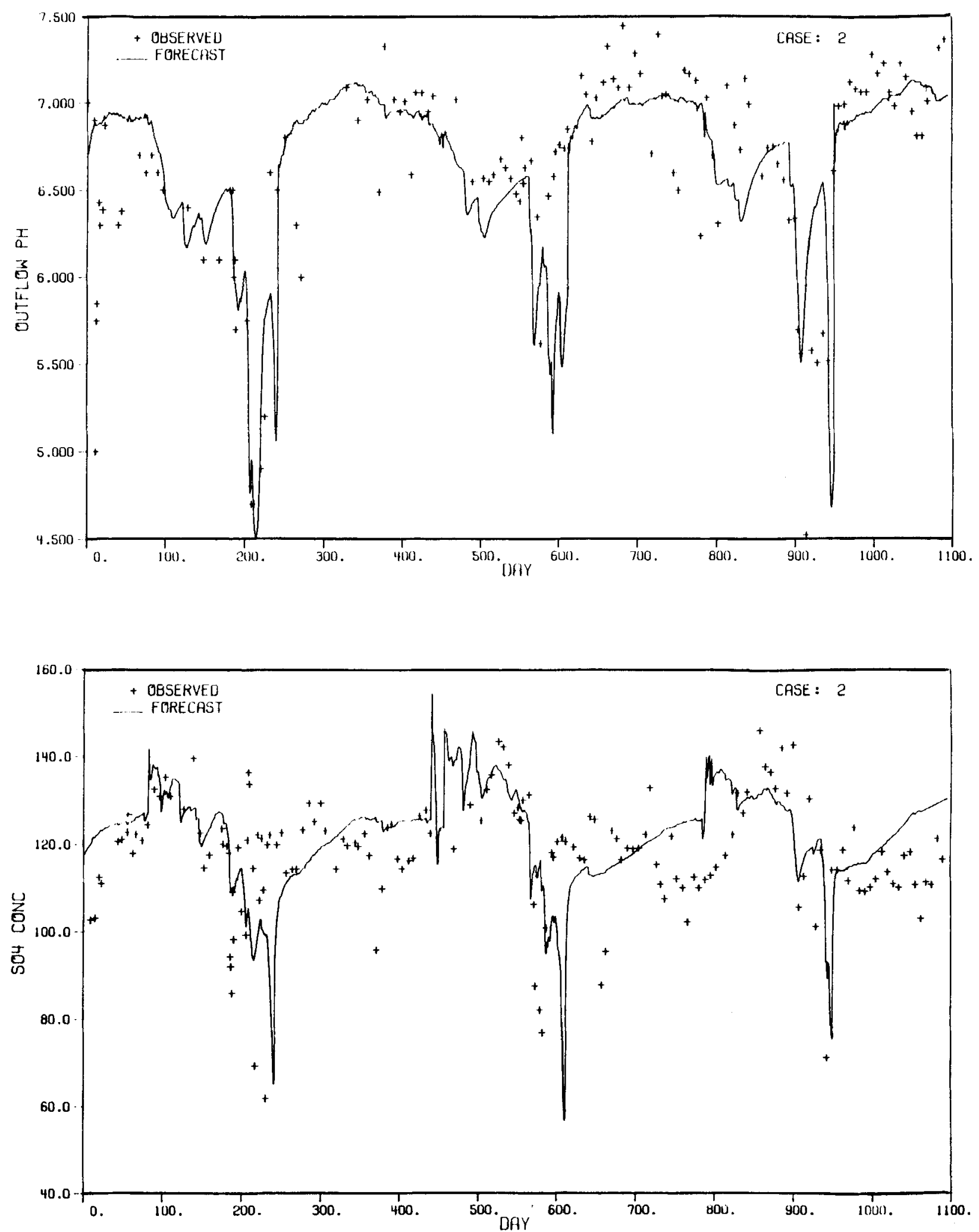

Figure 5. The observed and model predicted outflow chemistry (1 Sept., 1978 to 31 Aug., 1981). (A) (B) 
Table VI. Result of K-S test ( $p$ values) for the ILWAS model (hydrology portion) applied to the Walker Branch watershed

\begin{tabular}{lccccc}
\hline Variables & Range* & $\begin{array}{c}\text { CASE 1 } \\
R=0.5\end{array}$ & $\begin{array}{c}\text { CASE 2 } \\
R=0.55\end{array}$ & $\begin{array}{c}\text { CASE 3 } \\
\boldsymbol{R}=\mathbf{0 . 6}\end{array}$ & Sensitive \\
\hline SOIL MOISTURE & $0.5-1.5$ & 0.086 & 0.164 & 0.276 & NO \\
PERM & $0.5-1.5$ & 0.000 & 0.000 & 0.001 & YES \\
THICK & $0.5-1.5$ & 0.000 & 0.000 & 0.000 & YES \\
SMI & $0.5-1.5$ & 0.821 & 0.676 & 0.998 & NO \\
ETWGHT & $0.5-1.5$ & 0.288 & 228 & 0.603 & NO \\
SOLTMP & $0.5-1.5$ & 0.175 & 0.068 & 0.097 & NO \\
SNOWMELT & $0.5-1.5$ & 0.717 & 0.613 & 0.688 & NO \\
Number of acceptance & & 169 & 149 & 123 & \\
Number of rejection & & 131 & 151 & 177 & \\
\hline
\end{tabular}

* Multiple by the original value (Goldstein et al., 1984b).

\section{Application of the refined ILWAS to Walker Branch watershed}

In the following, the refined ILWAS model (with the systematic parameters estimation strategy) was tested on the Walker Branch watershed.

Because of the lack of precise input information some of the inputs were estimated from experience or were obtained from the literature. These inputs values need to be calibrated. A description of the manual adjustment of these inputs can be found in Chang (1988). The following paragraphs focus on the application of the joint strategy to the ILWAS model starting with the hydrologic portion of the model.

The six soil parameters (SOIL MOISTURE, PERM, THICK, SMI and ETWGHT) and the snowmelt coefficient (SNOWMELT) were chosen for RSA testing. Three different values of the subjective criterion were used to classify the results as acceptable or unacceptable, and they are shown in Table VI. The K-S test results show that the parameters PERM and THICK are sensitive, while the remaining parameters are insensitive for all there cases.

After using the RSA method to classify the parameters as sensitive or insensitive, the automatic parameter calibration technique was used to calibrate the sensitive parameters. The results show that the optimal values for the parameters PERM and THICK are 1.028 and 1.062 times their original values, respectively. The optimal $R$ value is as high as 0.705 . For verification the streamflow simulation was extended for the next two years as shown in Figure 6. It is seen that the model predicts the streamflow very well.

After fitting the streamflow discharge, the chemical portion of the model was adjusted to fit the streamflow chemistry. Since the air quality deposition and streamflow chemistry concentration of hydrogen and sulphate are not available, the calibration was performed on calcium and magnesium for the period of 1 September, 1969 to 31 August, 1970. Seven soil parameters which correlate with streamflow calcium and magnesium concentrations were chosen for testing their sensitivities by the RSA method. These are: CKEMG, $\mathrm{CKENH}_{4}$, CKEH, CKSO, CKMNRL, SOLION(6), and SOLION(7). The CKEMG, CKENH 4 , $\mathrm{CKEH}$ are the cation exchange coefficients for $\mathrm{Mg}, \mathrm{NH}_{4}$, and $\mathrm{H}$, respectively. CKSO is the anion adsorption coefficient for sulphate. CKMNRL is the weathering rate. SOLION(6) and SOLION(7) are the dissolved calcium and magnesium in soil solution, respectively. The ranges of all the parameters were set between 0.2 to 2.0 times their original values.

The acceptability criterion, $R$, was set equal to the average of the criteria $R 1$ and $R 2$ calculated from Equation 1 with $\bar{x}, \hat{x}$, and $x_{i}$ representing the mean, the estimate, and the observed values of $\mathrm{Ca}$ or of $\mathrm{Mg}$ concentration, respectively. Two $R$ values were used for classification criteria. The K -S test results are shown in Table VII. The parameters CKEMG, SOLION(3), and SOLION(7) are classified as sensitive, while the other parameters are insensitive.

Finally, the APCT method was used to calibrate the sensitive parameters. The results are shown in Figure 7. Comparing the results with those from the manual case (Table VIII), it is seen that a significant improvement of the streamflow $\mathrm{Ca}$ and $\mathrm{Mg}$ concentration simulation is obtained in the calibration period. 


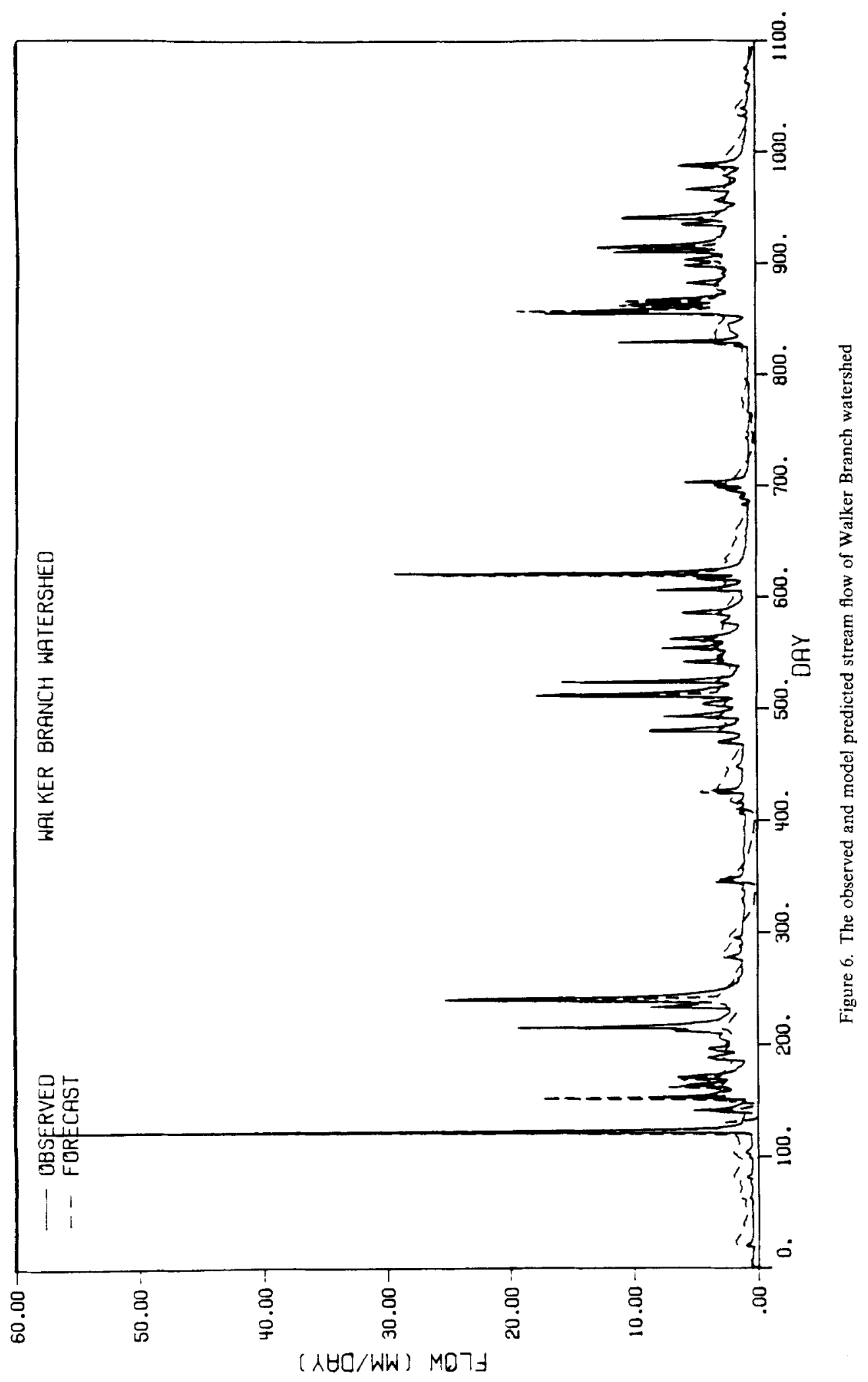


Table VII. Results of K-S test ( $p$ values) for the ILWAS model (chemical portion) applied to the Walker Branch watershed

\begin{tabular}{|c|c|c|c|c|}
\hline \multirow[t]{2}{*}{ Parameter } & \multirow[t]{2}{*}{ Range* } & \multicolumn{2}{|c|}{$R$} & \multirow[t]{2}{*}{ Sensitive } \\
\hline & & $-0 \cdot 3$ & -0.5 & \\
\hline CKEMG & $0.2-1.5$ & 0.000 & 0.000 & YES \\
\hline $\mathrm{CKENH}_{4}$ & $0.2-1.5$ & 0.676 & 0.494 & NO \\
\hline $\mathrm{CKEH}$ & $0.2-1.5$ & 0.219 & 0.029 & NO \\
\hline CKSQ & $0.2-1 \cdot 5$ & 0.199 & 0.479 & NO \\
\hline CKMNRL & $0.2-1.5$ & 0.320 & 0.267 & NO \\
\hline SOLION(6) & $0.2-1 \cdot 5$ & 0.000 & 0.001 & YES \\
\hline SOLION(7) & $0.2-1.5$ & 0.001 & 0.000 & YES \\
\hline Accepted number & & 120 & 162 & \\
\hline Unaccepted number & & 180 & 138 & \\
\hline
\end{tabular}

* Multiple of original value.
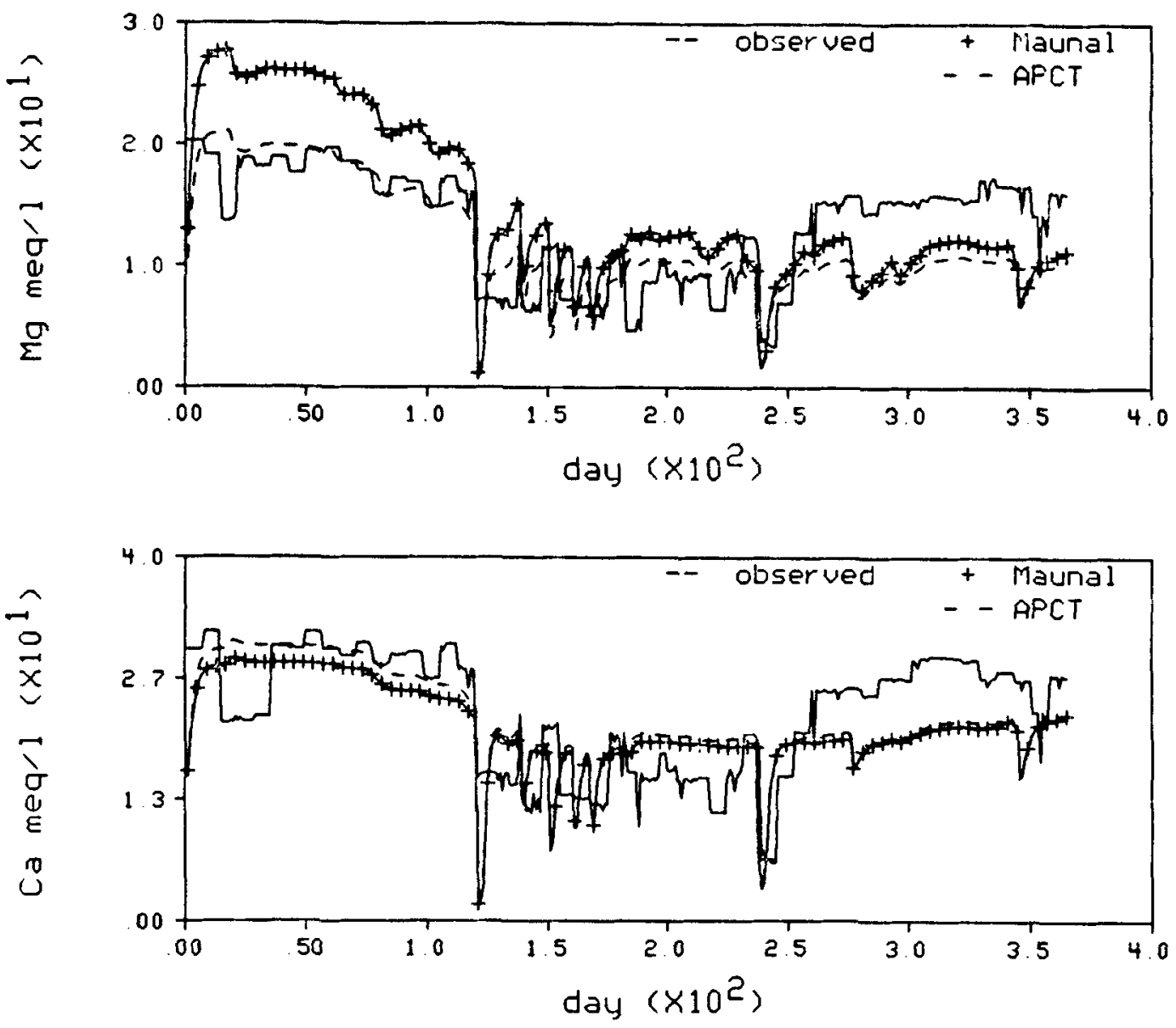

Figure 7. The observed and model simulated streamflow $\mathrm{Ca}$ and $\mathrm{Mg}$ concentrations 
Table VIII. The ILWAS model simulation results (chemical portion) applied to the Walker Branch watershed

\begin{tabular}{llcccccccc}
\hline Case & CKEMG & CKENH $_{4}$ & CKEH & CKSO & CKMNRL & $\begin{array}{c}\text { SOLION } \\
(6)\end{array}$ & $\begin{array}{c}\text { SOLION } \\
(7)\end{array}$ & $R$ & Corr \\
\hline Manual & $1.0^{*}$ & 1.0 & 1.0 & 1.0 & 1.0 & 1.0 & 1.0 & 0.221 & 0.638 \\
APCT & 0.521 & 1.0 & 1.0 & 1.0 & 1.0 & 1.0 & 0.646 & 1.205 & 0.322 \\
\hline
\end{tabular}

* Values shown in the table are ratios of the specified parameter values to their original values, except for the last two columns which show the acceptability criterion.

\section{CONCLUSION}

The joint strategy of regionalized sensitivity analysis and automatic parameter calibration technique for identifying the parameters in the ILWAS model, applied to the Panther Lake and Walker Branch watersheds, yields the following conclusions:

1. The RSA makes it possible to identify the important parameters. It is then possible to focus on the subset of objectively selected parameters and to use the automatic optimization method (APCT) for calibration.

2. The RSA method for testing the sensitivity of several soil hydrologic parameters (soil moisture, thickness, permeability, root distribution, initial soil temperature) yields similar results for both watersheds. The soil thickness is the only parameter which is sensitive. The soil permeability is moderately sensitive, while the soil moisture and initial soil temperature are insensitive. The root distribution is between moderately sensitive and insensitive.

3. Using the RSA method for testing sensitivity of several chemical parameters which relate to ion-exchange and weathering rate, it was found that the ion-exchange parameters were always more sensitive than the weathering rate parameter. Consequently, it is concluded that the chemical weathering process is less important than the ion-exchange process in determining the soil buffering capacity for short term simulation of the ILWAS model.

4. The application of the APCT for calibration of the parameters of the ILWAS model, using the Panther Lake data sets, showed that the sensitive parameters are all very close to their original measurement values. Also, the model fitted the observed outflow very well and fitted the outflow chemistry reasonably well. It may be concluded that original values of the important parameters are well chosen and that the APCT method succeeds in obtaining the optimal parameter values.

5. The application of the ILWAS model to the Walker Branch watershed shows that the implementation of the systematic parameter estimation strategy to the ILWAS model can save time for adjustment of the parameters and improves the model performance.

6. The strategy succeeds in classifying the parameters as sensitive or insensitive and reduces the number of model simulations for the calibration. It gives more confidence in the uniqueness of estimation parameter values and improves the likelihood of obtaining a global optimum parameter set.

7. It must be kept in mind that the relationships between optimized model parameters and the actual physical and chemical properties of watershed components may or may not correspond to the reality. There is no assurance that extrapolation of the model outside the range of parameter fitting will yield accurate results.

\section{ACKNOWLEDGEMENTS}

The authors wish to express their appreciation to Dr. R. Goldstein of EPRI for making the ILWAS code and Panther Lake watershed data available and to Dr. Dale Johnson, Ms. Julie Watts, and Mr. Jerry Jones of ORNL for making the Walker Branch watershed data available. Finally, the authors wish to thank the reviewers for their valuable comments. 


\section{REFERENCES}

April, R. and Newton, R. 1985. 'Influence of geology on lake acidification in the ILWAS watersheds', Water, Air, and Soil Pollution, 26, (4) $373-386$.

Chang, Fi-John 1988. Refinement of Hydrogeochemical Models of the Ecological Impact of Acid Deposition, Thesis presented to Purdue University in partial fulfilment of the requirements for the degree of Doctor of Philosophy.

Chen, C. W., Dean, J. D., Gherini, S. A., and Goldstein, R. A. 1982. 'Acid rain model: hydrologic module', J. Environ. Eng. ASCE, 108, $455-472$.

Chen, C. W., Hudson, J. M., Gherini, S. A., Dean, J. D., and Goldstein, R. A. 1983a. 'Acid rain model: canopy module', J. Environ. Eng. $A S C E, 109,585 \cdot 603$.

Chen, C. W., Gherini, S. A., Hudson, J. M., and Dean, J. D. 1983b. 'The Integrated Lake-Watershed Acidification Study. Vol. 1: model principles and application procedures', EPRI report, EA-322I.

Cronan, C. S. 1985. 'Biogeochemical influence of vegetation and soils in the ILWAS watersheds', Water, Air, and Soil Pollution, 26, (4) $355-372$.

Gherini, S. A., Mok, L., Hudson, J. M., Davis, G. F., and Chen, C. W. 1985. 'The ILWAS model: formulation and application', Water, Air, and Soil Pollution, 26, $425-459$.

Goldstein, R. A., Chen, C. W., and Gherini, S. A. 1985. 'Integrated Lake-Watershed Acidification: summary', Water, Air, and Soil Pollution, 26, (4) 327-338.

Goldstein, R. A., Gherini, S. A., Chen, C. W., Mok, L., and Hudson, J. M. 1984a. 'Integrated Lake-Watershed Acidification Study (ILWAS): mechanistic ecosystem analysis', Phil. Trans. R. Soc. London, B., 305, 409-425.

Goldstein, R. A. and Gherini, S. A. (Ed.) 1984b. 'The Integrated Lake Watershed Acidification Study. Vol. 4: summary of major results', EPRI report, EA-3221.

Harris, W. F. 1977. 'Walker Branch watershed: site description and research scope', in Correll, D. L. (Ed.), Watershed Research in Eastern North America: A Workshop to Compare Results, Vol. I, Chesapeake Bay Center for Environmental Studies, Smithsonian Institution.

Henderson, G. S., Huff, D. D., and Grizzard, T. 1977. 'Hydrologic characteristics of Walker Branch watershed', in Correll, D. L. (Ed.), Watershed Research in North America: A Workshop to Compare Results, Vol. I, Chesapeake Bay Center for Environmental Studies, Smithsonian Institution, 195-209.

Hines, W. W. and Montgomery, D. C. 1990. Probability and Statistics in Engineering and Management Science, Wiley, New York.

Hornberger, G. M. and Spear. R. C. 1981. 'An approach of the preliminary analysis of environmental systems', Journal of Environmental Management, 12,7 18.

Luenberger, D. G. 1984. Linear and Nonlinear Programming, Addison Wesley Publishing Company.

Sorooshian. Soroosh, 1978. Considerations of Stochastic properties in Parameter Estimation of Hydrologic Rainfall-Runoff Models, University of California, Los Angeles, Ph.D. Thesis. 